\title{
USEFULNESS OF SLEEP-DEPRIVED EEG IN THE DIAGNOSIS OF SEIZURE DISORDERS IN CHILDREN
}

\author{
SEYYED MOHAMMAD RAFIEI, M.D.
}

From the Department of Pediatric Neurology, Shiraz University of Medical Sciences, Shiraz, Iran.

\begin{abstract}
The provocative effects of sleep deprivation (SD) on patients with seizure disorder and on the electroencephalogram (EEG) are well known.The purpose of the study was to test its routine use and usefulness in the pediatric and adolescent age group with, or suspect of having, seizure disorder, especially those presenting with first unprovoked seizure.

Between September 2000 and November 2002, among patients referring to the author's clinic and the Pediatric Emergency Department of Nemazi Hospital, Shiraz, 598 children and adolescents were randomly assigned to a 10-minute surface EEG, either routinely, or after a period of partial or total SD. Those who refused or could not tolerate the SD procedure entered the routine group. The EEG's were analyzed for the presence of epileptic abnormality.

Of 598 patients, 544( 91\%) had clinical seizures; the rest (54, 9\%) were seizure suspects or had seizure "mimickers" (syncope, night terrors, pseudo-seizures, etc). Of seizure patients, 210 ( $38.6 \%$ ) suffered from a first unprovoked seizure, and the rest (334, 61.4\%) had more than one seizure episode at the time of EEG performance.

Abnormal epileptiform EEG's were more frequently seen in the group of seizure patients who were sleep-deprived before performing the EEG, as compared to the routine group. Conversely, more normal EEG's were seen upon routine performance of EEG ( $p$ value $<00001, \chi^{2}=76.5$ ).

Similarly, more abnormal sleep-deprived EEG's were seen in patients with first unprovoked seizure than when EEG was done routinely in this subgroup of patients. Patients with complex partial seizure had significantly more abnormal EEG's when subjected to $\mathrm{SD}(p<00001)$.

Older patients could tolerate SD better than the younger age group; so more routine EEG's had to be performed in the younger age group. Younger children could only tolerate partial SD. There was no difference in the yield of EEG in patients with absence epilepsy between the two groups. In 5 patients with juvenile myoclonic epilepsy, SD precipitated a generalized tonic-clonic seizure which necessitated acute antiepileptic drug administration to the seizure activity.

All patients with non-seizure episodes showed normal EEG's.

In conclusion SD can be safely applied in the work-up of selected pediatric patients with seizure disorder, especially in those with their first unprovoked seizure, in whom an abnormal EEG might dictate anti-epileptic drug therapy.

Not all children with seizure disorder need to undergo SD for EEG, as it may not
\end{abstract}


be necessary in some, and intolerable in others. In non-seizure episodes, if used in appropriate pediatric age groups, it can be very helpful to ensure that a seizure disorder is not present.

MJIRI, Vol. 18, No. 1, 21-27, 2004.

Keywords: Seizure Disorder, Epilepsy, Electroencephalography(EEG), Sleep Deprivation (SD).

\section{INTRODUCTION}

EEG is the most useful procedure in patients with suspicion of seizure disorder. Obtaining an EEG after a period of sleep deprivation (SD) is a well known procedure to increase the yield of EEG "positivity" and bring about the inter-ictal epileptiform activity. ${ }^{1-10}$ It is sometimes used as an activation procedure in a patient with seizure disorder whose first EEG has been negative; it is also recommended to be used routinely in children and adults $^{11,26}$ for the diagnosis of seizure disorder, or to induce sleep in children for obtaining sleep EEG's. ${ }^{11}$ Especially in a child with first unprovoked seizure, a positive EEG helps in determination of the risk of seizure recurrence, and the decision of drug therapy. ${ }^{12}$ In children with "seizure mimickers"-syncope,breath holding spells, emotional problems, pseudo-seizures $-{ }^{13}$ a negative EEG would be reassuring both to parents and physician, and obviates unnecessary anti-epileptic therapy. SD may activate interictal epileptiform discharges and provoke clinical seizures in susceptible individuals ${ }^{14}$ and is inconvenient or not feasible in infants and small children. ${ }^{15}$

The aim of the study was to see which patients benefit most from obtaining an EEG with SD, and whether it should be part of a routine EEG in every infant or child with or suspect of seizure disorder in our region.

\section{MATERIAL AND METHODS}

From September 2000 to November 2002, 598 infants,

Table I. Patient characteristics.

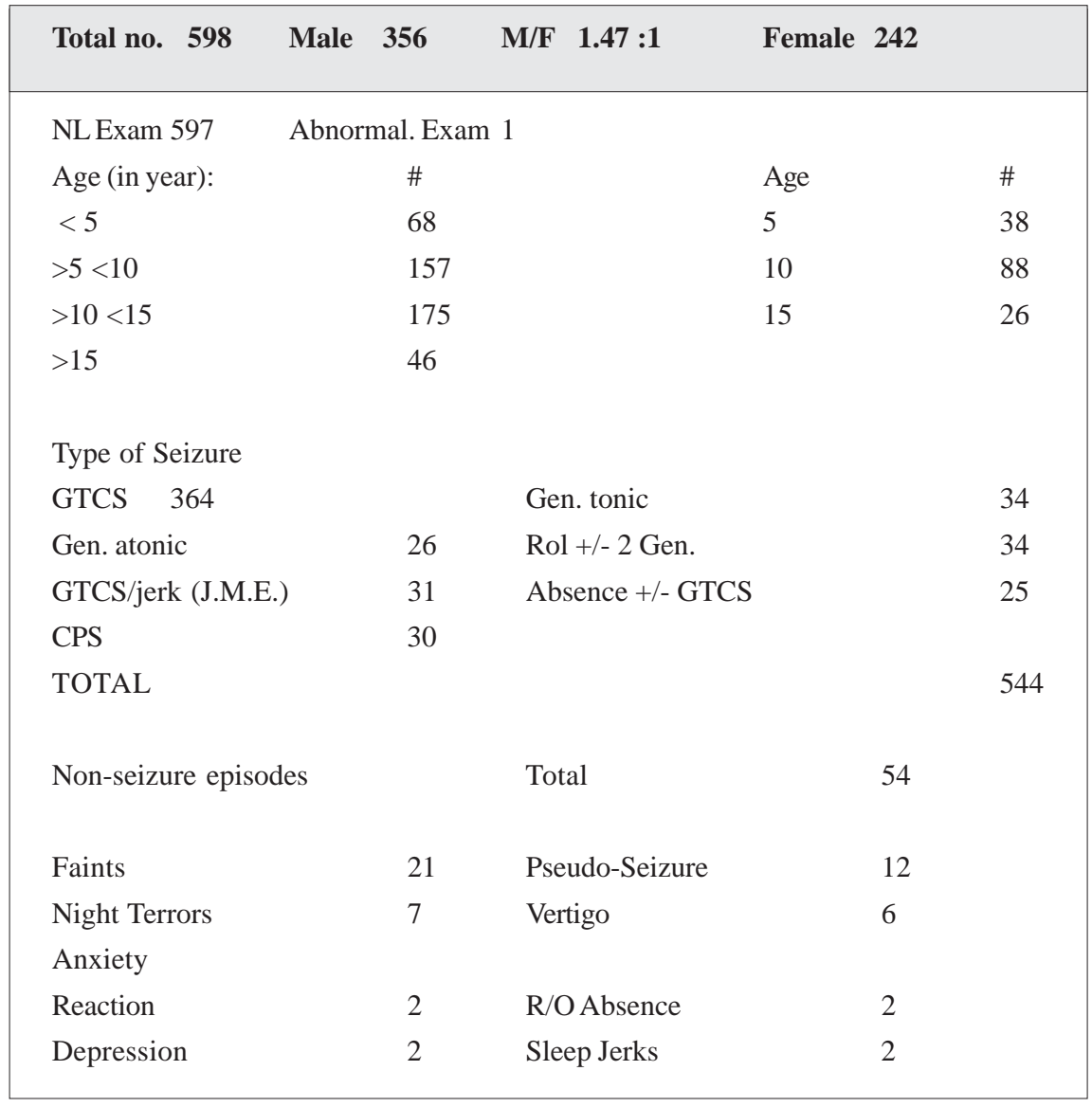




\section{S.M. Rafiei}

Table II. EEG abnormality vs. patient's condition at EEG performance.

\begin{tabular}{|c|c|c|c|}
\hline $\begin{array}{l}\text { Condition at } \\
\text { EEG }\end{array}$ & No. & Normal EEG & Abnormal EEG \\
\hline \multicolumn{4}{|l|}{ Routine } \\
\hline Awake & 253 & 154 & 99 \\
\hline Asleep & 27 & 18 & 9 \\
\hline Awake $\longrightarrow$ Asleep & 0 & 0 & 0 \\
\hline Total & 280 & 172 & 108 \\
\hline \multicolumn{4}{|c|}{ Sleep-Deprived } \\
\hline Awake & 133 & 50 & 83 \\
\hline Asleep & 61 & 8 & 53 \\
\hline Awake—>Asleep & 70 & 6 & 64 \\
\hline Total & 264 & 64 & 200 \\
\hline Total & \multicolumn{2}{|c|}{544} & \\
\hline
\end{tabular}

Table III. Frequency of EEG abnormality vs. number of seizures before EEG performance.

\begin{tabular}{|c|c|c|c|c|c|c|c|}
\hline First Seizure & $\mathrm{N}=210$ & Normal EEG & Abnormal EEG & $>1$ Seizures & $\mathbf{N}=334$ & Normal EEG & Abnormal EEG \\
\hline \multicolumn{8}{|l|}{ Routine } \\
\hline Awake & 91 & 64 & 27 & & 162 & 90 & 72 \\
\hline Asleep & 6 & 5 & 1 & & 21 & 13 & 8 \\
\hline Awake $\longrightarrow$ Sleep & 0 & 0 & 0 & & 0 & 0 & 0 \\
\hline Total & 97 & 69 & 28 & & 183 & 103 & 80 \\
\hline \multicolumn{8}{|l|}{ Sleep-Deprived } \\
\hline Awake & 46 & 20 & 26 & & 87 & 30 & 57 \\
\hline Asleep & 42 & 6 & 36 & & 19 & 2 & 17 \\
\hline Awake $\longrightarrow$ Sleep & 25 & & 25 & & 45 & 6 & 39 \\
\hline Total & 113 & 26 & 87 & & 151 & 38 & 113 \\
\hline
\end{tabular}

children, and adolescents, were randomly selected for the study from the author's private clinic patients, as well as those brought in to Nemazi Hospital Pediatric Emergency Room, Shiraz, with a chief complaint of one or more clinical seizure episode(s), or paroxysmal behaviors suspect of seizure disorder, for ruling out a seizure disorder. A thorough clinical evaluation, including detailed history and general physical and neurological examination was performed on each patient. Except for one case, patients with abnormal neurological examination were excluded from the study.

Patients were randomly advised to undergo either 1) a routine EEG, which according to the patient's age and cooperation, included: a wake, sleep, or awake -to-sleep tracing with or without a 3-minute hyperventilation and 1-30 Hz intermittent photic stimulation, or, 2) the same EEG after a period of SD.
The second group were advised to not go to sleep either for 24 hours before performing EEG (total SD), ${ }^{9}$ or in the case of younger children, to be kept awake as much as possible in the night before EEG performance, and to sleep only for no longer than 3 hours, and then be awakened (partial SD), and be present for the EEG laboratory, to undergo the EEG procedure, exactly as mentioned above.

The EEG machine was a 10-channel Nihon-Codon (Japan) paper EEG machine, as was shown in our previous report ${ }^{16}$ to be effective in showing epileptiform activity. Sleep was achieved either normally, or if needed, after a hypnotic, mainly promethazine syrup $0.5 \mathrm{mg} / \mathrm{kg}$. In those who could not tolerate, or refused, the SD, the EEG was obtained routinely at a later time.

A 10-minute EEG was thus obtained. It was visually analyzed for the presence of: 1 ) epileptic abnormality, i.e., spikes 
Sleep-Deprived EEG for Seizure Disorder Diagnosis in Children

Table IV. Type of seizure vs EEG abnormality.

\begin{tabular}{|lllll|}
\hline Seizure Type & \multicolumn{2}{l}{$\begin{array}{l}\text { Routine EEG } \\
\text { Normal }\end{array}$} & $\begin{array}{l}\text { Sleep Deprived EEG } \\
\text { Normal }\end{array}$ \\
& 2 & 13 & & 10 \\
\hline Absence +/- GTCS & 6 & 4 & 6 & 10 \\
Gen. Atonic & 8 & 3 & & 19 \\
CPS & 139 & 67 & 42 & 116 \\
GTCS & 4 & 6 & 6 & 15 \\
J.M.E. & 3 & 8 & 3 & 20 \\
Rol +/- GTCS & 10 & 7 & 7 & 10 \\
Gen. Tonic & & & & \\
\hline
\end{tabular}

GTCS : Generalized tonic-clonic seizures

ROl.: Rolandic seizures

J.M.E. : Juvenile myoclonic epilespy

Table V. Seizure “mimickers” and EEG at routine vs sleep deprivation.

\begin{tabular}{|c|c|c|c|c|c|c|c|c|}
\hline \multicolumn{9}{|c|}{ All EEG's taken were normal } \\
\hline Condition & No. & EEG : & $\mathbf{R} 1$ & $\mathbf{R} 2$ & R3 & SD1 & SD2 & SD3 \\
\hline Faint & 21 & & 7 & & & 10 & & 4 \\
\hline R/O Absence & 2 & & & & & 2 & & \\
\hline Anxiety & 2 & & & & & & & 2 \\
\hline Pseudo-Seizures & 12 & & 5 & & & 2 & & 5 \\
\hline Night Terrors & 7 & & & & & 7 & & \\
\hline Depression & 2 & & & & & 2 & & \\
\hline Sleep Jerk & 2 & & & & & 2 & & \\
\hline Vertigo & 6 & & 3 & & & & & 3 \\
\hline
\end{tabular}

R1: Routine, awake; R2: Routine, asleep; R3: Routine, awake $\longrightarrow$ sleep

SD1: Sleep-Deprived, Awake; SD2: SD, Asleep; SD3: SD, awake —> asleep

\& waves, poly spikes and waves, sharp-\&-slow waves, 2) non-epileptic abnormality, i.e., generalized or focal slowing. ${ }^{17}$ A data analysis was done.

\section{RESULTS}

Table I shows patient's characteristics. Of 598 in- fants, children, and adolescents, 544(91\%) had some form of clinical seizure activity, for the first time (210, 38.6\%), or more than one seizure episode (334, $61.4 \%$ ), before being subjected to EEG procedure. 54 patients (9\%) had non-seizure paroxysms, most commonly syncopal attacks. Except for one patient, all other patients had normal developmental and neurological evaluation. This 


\section{S.M. Rafiei}

patient, a 14 year old boy with congenital hemiparesis and mild developmental delay with two episodes of nocturnal generalized tonic-clonic seizures(GTCS), underwent a sleep-deprived EEG, first awake and then went to sleep during the EEG procedure, and his EEG proved abnormal. Of all patients with seizure disorder, GTCS predominated (364,66.9\%) (Tables I, IV).Other seizure types had equal frequencies.

Routine EEG's predominated somewhat over sleepdeprived ones; this was because some patients, especially those below 5 years, either refused, or could not tolerate sleep deprivation; so they underwent a routine EEG procedure.

As shown in Table II, the number of normal EEG's predominated in the routine group (172 vs. 64); conversely, in the sleep-deprived group, more abnormal EEG's were encountered (200 vs. 108) ( $p$ value $<0.0001)$

In the routine group, more EEG's had to be performed in awake state (253 vs. 133); in the sleep-deprived group,more sleep,and awake-to-sleep EEG's could be performed (131 vs. 27).

As shown in Table III, when patients with first seizure underwent a sleep-deprived EEG, more abnormal results were obtained (87 vs. 28); the same prevailed for patients with more than one seizure at the time of EEG performance (113 vs. 80). Slightly more sleep-deprived EEG's were performed on patients with first seizure (113 vs. 97); this may also partly account for more abnormal EEG's in this group.

When patients were sleep-deprived, more awake-tosleep EEG's could be performed (70 vs. zero); the majority of these EEG's were abnormal ( 64 out of 70) ( Table II). This procedure combines the "power" of sleep deprivation and sleep in provoking epileptiform discharges. ${ }^{21}$

When first-seizure group was compared to multi-seizure group regarding EEG abnormality, the second group had more abnormal EEG's whether or not sleep-deprived (80 vs. 28; 113 vs. 87).

When seizure type is tested versus frequency of EEG abnormality relative to condition at EEG performance, it seems that, a) for absence seizure it does not matter whether it is performed routinely or with SD; both show high percentage of EEG abnormality ( Table IV); b) in patients with generalized seizures, SD did increase the yield of EEG, whether or not primarily or secondarily generalized ( $p<0.0001)$. This is as well true for complex partial seizure (CPS), which showed high yield with SD (Table IV) $(p<0.0001)$; c) regarding juvenile myoclonic epilepsy (J.M.E.), although SD increased the yield, it provoked clinical GTCS in 5 patients, which necessitated acute anti-epileptic therapy, in the form of diazepam rectally or intravenously.

Regarding the age at which sleep SD could best be implemented, the older the child the easier it could be done, so most of the patients sleep-deprived were more than 5 years old. In younger children, only partial sleep deprivation could be performed.

SD - even partial - facilitated putting patients to sleep, and obviated the need to sedate the patients artificially.

Hyperventilation (H.V.) increased the EEG abnormality only in patients with absence seizure, equally in both groups; other patients in either group did not show any increase in EEG abnormality. This may reflect ineffective H.V. by the uncooperative or sleepy patients.

Early in the study, equal numbers of patients $(n=4)$ in either group showed increase in EEG abnormality with photic stimulation (P.S.). Later, P.S.did not enhance any further EEG abnormality in either group. So the differential effect of P.S. in the two groups was not further studied.

All patients with "seizure mimickers" had normal EEG's when sleep-deprived (Table V).

\section{DISCUSSION}

Obtaining EEG's using sleep SD is not a recent procedure. Rodin et al. noted high voltage paroxysmal activity in the EEG's of 16 normal subjects following 120 hours of SD. ${ }^{1}$ Cases of convulsion in normal subjects (pilots and soldiers) after SD were later reported..$^{2-5}$ SD has a very low false-negative rate (1.2-2.2 \%)..$^{2,4,6,7} \mathrm{SD}$ has activating effects on interictal epileptiform discharges over and above the effects of sleep per se. ${ }^{8,10,27,28}$ It may obviate the need for a second routine EEG when the first one is normal. ${ }^{23,24,25}$

SD may also provide a useful way of inducing sleep in children, avoiding sedative artifacts on the EEG background. ${ }^{11}$ However, the effect of SD on EEG is independent of the effect of sleep itself. ${ }^{10}$

As is well known, sleep unravels or potentiates epileptiform activity on EEG. ${ }^{14}$ Activating effects of SD may be more pronounced in children compared to adults. ${ }^{20,22}$

So it seems prudent to obtain a sleep deprived awake EEG followed by sleep, in children with clinical impression of seizure activity, or paroxysmal behavior for which seizure disorder is to be ruled out. This obviates the need to perform a second EEG in those whose routine EEG has been normal, and the suspicion of clinical seizure is still high. Potential "side effects" of SD include: ${ }^{15}$ stress and inconvenience of SD, especially in children, potential accident to patient when en route to EEG laboratory due to sleepiness; this means that another person should accompany the patient, which implies loss of work or school for two persons, and minor chance of seizure provocation.

Patients with known seizure disorder experience increase in seizure frequency when sleep-deprived. Acti- 
vation of seizure discharges, and increase in seizure after SD is a known phenomenon. ${ }^{14}$

Patients with juvenile myoclonic seizure may be particularly susceptible to the seizure-provoking effect of $\mathrm{SD}$, and in them, GTCS activity may be precipitated if sleep-deprived, ${ }^{30}$ as shown in this study. Therefore, a great precaution is advised when counseling these patients regarding obtaining an EEG with SD.

The EEG laboratory and parents should be provided with necessary information and guidance to abort the seizure, if one occurs in the sleep deprived patient before, during or after the EEG procedure. It is probably better to admit these patients at hospital, sleep-deprive them in the ward, and perform the EEG with close monitoring. Or, if the history is highly suggestive of juvenile myoclonic epilepsy, to perform a routine EEG, or start anti-epileptic drugs without performing EEG.

So based on our results, we recommend a sleep deprived EEG in children and adolescents who present with first unprovoked seizure.

Sleep deprivation may be inconvenient for children, ${ }^{15}$ and may precipitate clinical seizure in patients with seizure disorder. ${ }^{14,30}$ GTCS activity may be precipitated if the patient is sleep - deprived. ${ }^{30}$ Children with absence seizures might not need a sleep-deprived EEG, as the routine awake EEG with hyperventilation usually unravels the typical EEG abnormality in this group of patients. Patients with juvenile myoclonic epilepsy may be exempted from SD before performing EEG, as it may provoke a clinical GTCS.

In infants and children and adolescents who are "seizure mimickers”, ${ }^{13}$ a negative sleep deprived EEG may be more assuring to the parents and clinicians, and obviates unnecessary and potentially harmful anti-epileptic administration.

Infants and children below 5 years of age may be partially sleep-deprived, merely to induce natural sleep and obviate the need for sedation, which may impart artifact on EEG tracing.

\section{CONCLUSION}

With minor exceptions, SD can safely be employed in the protocol for EEG recording in children. It is especially useful in children with first seizure episode, when an abnormal EEG result may dictate initiation of antiepileptic therapy.

Patients with absence epilepsy may not need it; in patients with juvenile myoclinic epilepsy, it is advisable not to employ it for the potential danger of provoking a clinical GTCS episode. In younger children partial sleep SD is advised.

\section{ACKNOWLEDGEMENT}

The author is especially thankful to the staff of
Motahhari Clinic EEG Laboratory for their preparation of the patients' EEG's and to Dr Sarafraz and Ms Baghaee for their guidance in statistical analysis.

\section{REFERENCES}

1. Rodin E, Luby ED, Gottlieb JS: The electro-encephalogram during prolonged experimental sleep deprivation. EEG \& Clinical Neurophysiology 14: 544-551, 1962

2. Bennet DR: Sleep deprivation and major motor convulsions. Neurology 13: 953-958, 1963.

3. Bennet DR, Mattson RH, Zitter FA et al: Sleep deprivation: Neurological and electroencephalographic effects. Aerospace Medicine 35: 888-890, 1964.

4. Bennet DR, Zitter FA, Lisk EA: Electroencephalographic effects of sleep deprivation in flying personnel. Neurology 19: 375-379, 1969.

5. Gundeson CH, Dunne PB: Sleep deprivation seizures. Neurology 23: 678-686, 1973.

6. Geller MR,Gourdji N, Chisthoff N, et al :The effects of sleep deprivation on the EEGs of epileptic children. Dev Med Child Neurol 11: 771-776, 1969.

7. Welch LK, Stevens JB: Clinical value of the electroencephalogram following sleep deprivation. Aerospace Medicine 42: 349-351, 1971.

8. Fountain NB, Kim JS, Lee SI: Sleep deprivation activates epileptiform discharges independent of activating effects of sleep. J Clin Neurophysiology 15: 60-75, 1998.

9. Neidermyer E: Sleep and EEG. In: Neidermyer E, Da Silva FL, (eds). Electroencephalography: Basic Principles, Clinical Applications, and Related Fields. Fourth Edition, Philadelphia: Williams \& Wilkins Company, pp. 175-176, 1999.

10. Ellingson RJ, Wilken K, Bennett DR: Efficacy of sleep deprivation as an activating procedure in epilepsy patients. J Clin Neurophysiol 15: 69-75, 1984.

11. Liamsuwan S, Gratten-Smith G, Fagan E, Bleasel A, Anthony J: The value of partial sleep deprivation as a routine measure in pediatric electroencephalography. Journal of Child Neurology 15(1): 26-29, 2000.

12. Hirtz D, Ashwal S, Berg A, et al: Practice parameter: evaluating a first nonfebrile seizure in children. Report of the Quality Standards Subcommittee of the American Academy of Neurology, the Child Neurology Society, and the American Epilepsy Society. Neurology 55(September): 616-623, 2000.

13. Haslam RH: Conditions that Mimic Seizures. In: Behrman RE, Kliegman RM, Jenson HB, (eds). Nelson Textbook of Pediatrics, $16^{\text {th }}$ Edition, Philadelphia:W.B. Saunders Company, pp. 1829-1832, 2000.

14. Kotagal P: The relation between sleep and epilepsy. Seminars in Pediatric Neurology 8(4) (December): 241-250, 2001.

15. Glick TH: The sleep-deprived electroencephalogram: evidence and practice. Archives of Neurology 59 (8): 1235- 


\section{S.M. Rafiei}

1239, Aug 2002.

16. Firoozifard OR, Rafiei SM: Value of inter-ictal surface EEG in the diagnosis of seizure disorders in children: a pilot study. Medical Journal of the Islamic Republic of Iran 14(3): 217-221, November 2001.

17. Neidermyer E: Abnormal EEG patterns: Epileptic and paroxysmal. In: Neidermyer E, DA Silva FL, (eds), Electroencephalography: Basic Principles, Clinical Applications, and Related Fields. Fourth Edition, Philadelphia: Lippincott-Wiliams \& Wilkins, pp. 235-260, 1999.

18. Berg AT, Shinnar S: The risk of seizure recurrence following a first unprovoked seizure, a quantitative review. Neurology 41(7): 965-72, 1991.

19. Shinnar S, Kang H, Berg AT, et al: EEG abnormalities in children with first unprovoked seizure. Epilepsia 35: 471476, 1994.

20. Tartara A, Moglia A, Manni R, et al: EEG findings in sleep deprivation. Eur Neurol 19: 330-334, 1980.

21. El-Ad B, Neufold MY, Korczyn AD: Should sleep EEG record always be performed after sleep deprivation? EEG Clin Neurophysiol 90: 313-315, 1994.

22. Degan R: A study of the diagnostic value of waking and sleep EEG's after sleep deprivation in epileptic patients on anticonvulsive therapy. Electroencephalography and Clinical Neurophysiol 49: 577-584, 1980.

23. Ajmone-Marsan C, Zivin LS: Factors related to the occur- rence of typical paroxysmal abnormalities in the EEG records of epileptic patients. Epilepsia 28: 331-334, 1987.

24. Carpay YA, de Weed AW, Schimsheimer RJ, et al: The diagnostic yield of second EEG after partial sleep deprivation: A prospective study in children with newly diagnosed seizures. Epilepsia 38: 595-599, 1997.

25. Salinsky M, Kanter R, Dasheif RM: Effectiveness of multiple EEG's in supporting the diagnosis of epilepsy: An operational curve. Epilepsia 28: 331-334, 1987.

26. Lowenstein DH: Seizures and Epilepsy. In: Braunwald E, Faucia AS, Kasper DL, Hauser SL, Long DL, Jameson JL, (eds)., Harrison's Principles of Internal Medicine, $15^{\text {th }}$ Edition, New York: Mc GrawHill Co, pp. 2354-2369, 2001.

27. Mendez M, Radtke RA: Interaction between sleep and epilepsy. J Clinical Neurophysiol 15: 69-75, 1998

28. Rowan AJ, Velhuisen RJ, Nagelkerke NJD: Comparative evaluation of sleep deprivation and sedated sleep EEGs as diagnostic aids in epilepsy. Electroencephalogr Clin Neurophysiol 54: 357-364, 1982.

29. Binnie CD, Stephan H: Modern electroencephalography: its role in epilepsy management. Clin Neurophysiol 110: 1671-1697, 1999.

30. Borgeoise BFD: Generalized Seizures, In: Maria BL, (ed), Current Management in Child Neurology. ( $2^{\text {nd }}$ edition) Hamilton London: BC Decker Inc, pp. 113-121, 2002. 